\title{
Can the birth of a large infant predict risk for atherosclerotic vascular disease in the mother?
}

\author{
J.Spjuth $^{1}$, G. Larsson ${ }^{2}$, P. Nilsson-Ehle ${ }^{3}$, B. Schersten ${ }^{4}$ and B. Åstedt ${ }^{5}$ \\ Departments of ${ }^{1}$ Internal Medicine, ${ }^{2}$ Obstetrics and Gynaecology, Central Hospital, Karlskrona; \\ Departments of ${ }^{3}$ Clinical Chemistry, ${ }^{4}$ Community Health Sciences, ${ }^{5}$ Obstetrics and Gynaecology, University of Lund, \\ University Hospital, Lund, Sweden
}

\begin{abstract}
Summary. We have previously demonstrated that women who had given birth to large infants had a six-fold increased risk of developing Type 2 (non-insulin-dependent) diabetes mellitus compared with a control group matched for age and parity. However, the patients were extremely obese which explained, in part, the increased risk. In the present investigation we studied whether the delivery of large infants correlated with risk factors for atherosclerotic vascular disease other than obesity and diabetes, and therefore could serve as early markers for syndrome $X$. The study consisted of 73 women who 20-27 years earlier had given birth to large infants weighing $4,500 \mathrm{~g}$ or more. Another group of 73 women matched for age, parity and BMI who had delivered infants weighing less than 4,500 g within a 3-month period served as a control group. Of these 73 patient/control pairs, $48(66 \%)$ were able to participate in the investigation. Mean age was 52.2 years (range 40-66 years). No differences were noted for
\end{abstract}

family history of diabetes and medication prescribed for vascular disease between the groups. An oral glucose tolerance test was performed and glucose, insulin and C-peptide at 0 and $2 \mathrm{~h}$ were estimated. Triglycerides, cholesterol, LDL and HDL cholesterol were analysed at baseline. We found no tendency towards hyperinsulinaemia and hyperglycaemia in the patients and both groups had the same relative increase in levels of insulin and C-peptide. No difference between the groups regarding manifest symptoms of vascular disease, either in blood pressure or in proteinuria were observed. The only risk factor for atherosclerotic vascular disease identified was a significantly lower concentration of HDL in the patient group.

Key words: Macrosomia, large infant, atherosclerotic vascular disease, insulin resistance, hypertension, hyperlipoproteinaemia.
Primary preventive measures against, as well as treatment of, atherosclerotic vascular disease could be more effective if they were implemented earlier in the course of the disease. Therefore, both from an individual and a public health perspective it is important to find markers which identify individuals at risk. Apart from genetic predisposition most risk factors such as hypertension, diabetes mellitus and hyperlipoproteinaemia have the drawback of being diagnosed late when the pathophysiologic mechanisms are well established and organic damage may already have occurred.

In a previous study [1] we reported that a high birth weight of the child correlated with one of the risk factors, namely diabetes. In a prospective study of 270 women who had given birth to large infants $(\geq 4,500 \mathrm{~g})$, we could demonstrate that these women had a six-fold increased risk of developing Type 2 (non-insulin-dependent) diabetes 20-27 years later. However, the patients were extremely obese and this could explain, in part, the increased risk.
Given these relationships, it seemed of interest to investigate if the delivery of large infants correlates with risk factors for atherosclerotic vascular disease other than obesity and diabetes. Recently, much interest has focused on the so-called syndrome $X$ as described by Reaven [2]. This syndrome includes hypertension, increased peripheral insulin resistance, hyperinsulinaemia, glucose intolerance, increased concentrations of triglycerides and LDL as well as lowered concentrations of HDL and is strongly correlated to premature cardiovascular disease.

In the present paper we investigate whether having given birth to a large infant is predictive of syndrome $X$.

\section{Subjects and methods}

\section{Patients}

The study material consisted of 73 of the 270 women who had given birth to large infants $(\geq 4,500 \mathrm{~g})$ at the Department of Obstetrics and Gynaecology, Central Hospital, Karlskrona, Sweden between 
Table 1. Distribution of body weight, height, BMI and blood pressure in patients and control subjects (for definition see Subjects and methods)

\begin{tabular}{lccl}
\hline & Patients & $\begin{array}{l}\text { Control } \\
\text { subjects }\end{array}$ & $\begin{array}{l}\text { Level of } \\
\text { significance }\end{array}$ \\
\hline Weight $(\mathrm{kg})$ & $69.2(8.1)$ & $70.0(10.0)$ & NS \\
Height $(\mathrm{cm})$ & $166.7(5.1)$ & $162.1(4.4)$ & $p<0.0001$ \\
BMI & $24.9(3.0)$ & $26.6(3.9)$ & $p<0.0001$ \\
$\begin{array}{l}\text { Systolic blood pressure } \\
\text { (mm Hg) }\end{array}$ & $126.3(18.5)$ & $130.6(19.0)$ & NS \\
$\begin{array}{l}\text { Diastolic blood pressure } \\
\text { (mm Hg) }\end{array}$ & $79.1(10.1)$ & $79.2(9.3)$ & NS \\
\hline
\end{tabular}

Values shown are mean and SD is given in parentheses

Table 2. Distribution of glycemic parameters in patients and control subjects (for definition see Subjects and methods)

\begin{tabular}{llll}
\hline & Patients & $\begin{array}{l}\text { Control } \\
\text { subjects }\end{array}$ & $\begin{array}{l}\text { Level of } \\
\text { significance }\end{array}$ \\
\hline Glucose $(0 \mathrm{~h})(\mathrm{mmol} / \mathrm{l})$ & $4.36(0.56)$ & $4.48(0.56)$ & $\mathrm{NS}$ \\
Glucose $(2 \mathrm{~h})(\mathrm{mmol} / \mathrm{l})$ & $5.21(1.57)$ & $5.60(1.17)$ & $\mathrm{NS}$ \\
serum-insulin $(0 \mathrm{~h})(\mathrm{nmol} / \mathrm{l})$ & $0.05(0.03)$ & $0.10(0.05)$ & $p<0.0001$ \\
serum-insulin $(2 \mathrm{~h})(\mathrm{nmol} / \mathrm{l})$ & $0.19(0.16)$ & $0.39(0.27)$ & $p<0.0001$ \\
serum-insulin $(2 \mathrm{~h}) /$ & & & \\
serum-insulin $(0 \mathrm{~h})$ & 3.8 & 3.9 & \\
C-peptide $(0 \mathrm{~h})(\mathrm{nmol} / \mathrm{l})$ & $0.37(0.17)$ & $0.84(0.29)$ & $p<0.0001$ \\
C-peptide $(2 \mathrm{~h})(\mathrm{nmol} / \mathrm{l})$ & $0.96(0.52)$ & $2.26(5.27)$ & $p=0.017$ \\
C-peptide $(2 \mathrm{~h}) /$ & & & \\
C-peptide $(0 \mathrm{~h})$ & 2.6 & 2.7 & \\
\hline
\end{tabular}

Values shown are mean and SD is given in parentheses

1958 and 1965 . The control group comprised 73 women individually matched for age, parity and BMI who had delivered infants weighing less than 4,500 $\mathrm{g}$ within 3 months of the patient group. BMI was not allowed to differ by more than two units. These 73 pairs represent all the patients and control subjects from the original material fulfilling the above-mentioned matching criteria. None of the patients or control subjects had been diagnosed with diabetes. A total of 48 patient/control pairs $(66 \%)$ accepted to participate in the investigation.

Both patients and control subjects were interviewed by the same technician according to a specific protocol. Questions concerning family history of diabetes, obstetric history, previous diseases and surgery, medication and menstrual data were asked. Height, weight and blood pressure were measured and an oral glucose tolerance test using a glucose load of $1 \mathrm{~g} / \mathrm{kg}$ body weight (maximum $70 \mathrm{~g}$ glucose) was performed. Blood samples for glucose, insulin and C-peptide were drawn at $0 \mathrm{~h}$ and $2 \mathrm{~h}$. Blood samples for analyses of triglycerides, total cholesterol, LDL and HDL cholesterol were taken at $0 \mathrm{~h}$.

\section{Analytical methods}

The glucose oxidase method was used for analysis of the glucose concentration. Commercially available radioimmunoassay kits from Novo (Copenhagen, Denmark) were used for determination of serum(s) insulin and s-C-peptide [3, 4].

Plasma concentrations of triglycerides and cholesterol were measured enzymatically using reagents from Boehringer-Mannheim (Mannheim, FRG). HDL cholesterol concentrations were determined in the supernatant obtained after precipitation of VLDL and $\mathrm{LDL}$ with dextran sulphate and $\mathrm{MgCl}_{2}$ [5]. LDL concentrations were calculated according to Friedewald et al. [6].

\section{Statistical analysis}

Student's $t$-test and the chi-square test were used to analyse the data. All values were two-tailed. A $p$ value less than 0.05 was considered significant.

\section{Results}

Mean age of the 48 patient/control pairs was 52.2 years (range 40-66 years). Twenty-seven patients and 22 control subjects were still menstruating. Twenty-four of 48 patients and 17 of 48 control subjects had a family history of diabetes. In 17 patients and 14 subjects respectively, there was a positive family history for Type 2 diabetes. None of these differences was statistically significant. Three patients and three control subjects were presently being treated for hypertension with beta-blocking agents, thiazides or both. Seven patients and six control subjects were taking hormone replacements for menopausal symptoms. Urinary analysis for glucose and protein were negative for all patients and control subjects.

Distributions of body weight, height, BMI, systolic and diastolic blood pressure are shown in Table 1. Although the average body weight was similar in patients and control subjects, the patients were taller and, consequently, had significantly lower $(p<0.0001)$ BMI.

Data related to carbohydrate metabolism are given in Table 2. There were no significant differences in fasting blood glucose concentrations or in the response to the glucose tolerance test. However, both insulin and C-peptide concentrations were lower in patients than in control subjects before and after glucose intake. The relative rise in insulin and C-peptide levels after glucose intake, however, was similar.

Serum lipid and lipoprotein concentrations are summarized in Table 3 . The control group had significantly higher levels of cholesterol and triglycerides. The lower cholesterol concentrations in the patients could be largely accounted for by the significantly lower concentrations of HDL cholesterol, while the levels of LDL cholesterol

Table 3. Distribution of serum lipid and lipoprotein concentrations in patients and control subjects (for definition see Subjects and methods)

\begin{tabular}{|c|c|c|c|}
\hline & Patients & $\begin{array}{l}\text { Control } \\
\text { subjects }\end{array}$ & $\begin{array}{l}\text { Level of } \\
\text { significance }\end{array}$ \\
\hline serum-cholesterol $(\mathrm{mmol} / \mathrm{l})$ & $6.18(1.15)$ & $6.75(1.22)$ & $p=0.023$ \\
\hline $\begin{array}{l}\text { serum-HDL-cholesterol } \\
(\mathrm{mmol} / \mathrm{l})\end{array}$ & $0.99 \quad 0.25$ & $1.20 \quad 0.26$ & $p<0.0001$ \\
\hline $\begin{array}{l}\text { serum-LDL-cholesterol } \\
(\mathrm{mmol} / \mathrm{l})\end{array}$ & 4.681 .08 & 4.891 .07 & NS \\
\hline serum-triglycerides (mmol/l) & 1.150 .50 & 1.390 .60 & $p=0.022$ \\
\hline LDL/HDL & 4.72 & 4.07 & \\
\hline
\end{tabular}

Values shown are mean and SD is given in parentheses 
were not significantly different between patients and control subjects.

\section{Discussion}

It is well known that the development of atherosclerotic vascular disease is associated with certain derangements in carbohydrate and lipid metabolism. Insulin resistance leading to hyperinsulinaemia can induce dyslipidaemia and damage to the vessel wall, and is frequently associated with increased arterial blood pressure [7-10]. Gestational diabetes implies increased risk later in life of developing hyperinsulinaemia, impaired glucose tolerance and Type 2 diabetes. The altered carbohydrate metabolism during pregnancy is accompanied by increased growth in the child [11-13]. A pregnancy which has resulted in a large baby might therefore be an indicator of a deranged carbohydrate metabolism. This may predict a tendency of developing the above-mentioned risk factors later in life which comprise syndrome $\mathrm{X}$.

Concerning carbohydrate metabolism we found no tendency towards hyperinsulinaemia and hyperglycaemia in the patients. On the contrary, the control subjects had significantly higher insulin and C-peptide levels in both the fasting state and after $2 \mathrm{~h}$. Correspondingly, the glucose concentration tended to be higher in control subjects, however not significantly. This may be explained by different adiposity between the groups.

The matching of the subjects resulted in a difference of 1.7 units in BMI which could be explained solely by the fact that control subjects were $4.6 \mathrm{~cm}$ shorter than patients. Thus, the control subjects were more obese. Both groups had however the same relative increase in levels of insulin and C-peptide indicating an equivalent beta-cell function but a more pronounced peripheral insulin resistance in control subjects, in accordance with their larger amount of adipose tissue $[14,15]$. The large difference between groups is however surprising and it is difficult to find a satisfactory explanation.

Differences in the lipid and lipoprotein concentrations partly followed the above-mentioned pattern. The control group subjects with higher insulin levels also had higher levels of triglyceride and cholesterol as might be expected. Since plasma HDL concentrations are, in general, inversely related to plasma triglyceride levels, and, furthermore, tend to be lower in obese subjects, we had expected lower values in the control group [16, 17]. However, the patients turned out to have significantly lower concentrations of HDL when compared with control subjects. This observation leads to the question of whether the birth of a large-for-gestational age infant can predict atherosclerotic vascular disease in the mother. Low levels of HDL are found not only in patients with manifest Type 2 diabetes but also during the development of impaired glucose tolerance and furthermore, in healthy relatives to patients with Type 2 diabetes and thus, might be caused by a genetic factor [18]. The lower HDL concentration in patients could not be explained by difference in height. There was no correlation between height and HDL concentration in the material.
We found no difference between groups regarding manifest symptoms of vascular disease either in systolic or diastolic blood pressure or in proteinuria. Family history of diabetes and medication, prescribed for vascular disease were the same in both groups. Only three women were on antihypertensive medication in each group.

In conclusion we have, in a previous paper [1], demonstrated that women who had given birth to a large infant had a considerably increased risk of developing Type 2 diabetes compared with the control group matched for age and parity. However, the patients were extremely obese and this explained, in part, the increased risk. In the present paper after also matching for BMI, we found that women who had given birth to large babies had a significantly lower concentration of HDL. This was the only risk factor of atherosclerotic vascular disease which was identified in these patients. Otherwise, we found no indication that giving birth to a large-for-gestational age infant predicts development of syndrome $\mathrm{X}$. This finding as far as we know, has not been previously reported and should be confirmed by others.

Acknowledgements. This study was supported by grants from the Swedish Diabetes Association, Stockholm, the Swedish Medical Research Council and the Diabetes Association of Blekinge County, Karlskrona, Sweden.

\section{References}

1. Larsson G, Spjuth J, Ranstam J, Vikbladh I, Saxtrup O, Ȧstedt B (1986) Prognostic significance of birth of large infant for subsequent development of maternal non-insulin-dependent diabetes mellitus. A prospective study over 20-27 years. Diabetes Care 9:359-364

2. Reaven GM (1988) Role of insulin resistance in human disease. Diabetes 37: 1595-1607

3. Heding LG (1966) A simplified insulin radioimmunoassay method. In: Donato L, Milhaud G, Sirchis J (eds) Labelled proteins in tracer studies. Euratom, Brussels, pp 345-350

4. Heding LG (1975) Radioimmunological determination of human C-peptide in serum. Diabetologia 11: 541-548

5. Finlay PR, Schifman RB, Williams RJ, Lichti DA (1978) Cholesterol in high-density lipoprotein: use of $\mathrm{Mg}^{2+} /$ dextran sulfate in its enzymic measurement. Clin Chem 6: 931-933

6. Friedewald WT, Levy RJ, Fredrickson DS (1972) Estimation of concentration of low-density lipoprotein cholesterol in plasma, without use of the preparative ultracentrifuge. Clin Chem 18: 499-502

7. Abbot WGH, Lillioja S, Young AA et al. (1987) Relationships between plasma protein concentrations and insulin action in an obese hyperinsulinaemic population. Diabetes 36: 897-904

8. Gary A, Helderman H, Koffler M, Ayuso R, Rosenstock J, Raskin $\mathrm{P}$ (1988) Relationships between lipoprotein levels and in vivo insulin action in normal young white men. Metabolism 37: 982987

9. Ferrannini E, Buzzigoli G, Bonadonna R et al. (1987) Insulin resistance in essential hypertension. $\mathrm{N}$ Engl J Med 317: 350-357

10. Modan M, Halkin H, Almog S et al. (1985) Hyperinsulinemia: a link between hypertension, obesity and glucose intolerance. J Clin Invest 75: 809-817

11. O'Sullivan JB (1984) Subsequent morbidity among gestational diabetic women. In: Sutherland HW, Sowers JM (eds) Carbohydrate metabolism in pregnancy and the newborn. Churchill Livingstone, Edinburgh, pp 174-180 
12. Grant PT, Oats JN, Beischer NA (1986) The long-term follow-up of women with gestational diabetes. Aust N Z J Obstet Gynecol 26: $17-22$

13. Horger EO III, Miller MC III, Conner ED (1975) Relation of large birthweight to maternal diabetes mellitus. Obstet Gynecol 45: $150-154$

14. Olefsky JM, Kolterman OG, Scarlett J (1982) Insulin action and resistance in obesity and non-insulin-dependent type II diabetes mellitus. Am J Physiol 343: 15-30

15. Björntorp P (1988) The association between obesity, adipose tissue distribution and disease. Acta Med Scand 723 [Suppl]: $121-134$

16. Uusitupa M, Siitonen O, Voputilainen E et al. (1986) Serum lipids and lipoproteins in newly diagnosed non-insulin-dependent (type II) diabetic patients with special reference to factors influencing HDL-cholesterol and triglyceride levels. Diabetes Care 9: $17-22$
17. Salonen JT (1990) Epidemiology of high density lipoproteins and atherosclerosis. In: Carlson LA (ed) Disorders of HDL. SmithGordon, London, pp 145-154

18. Taskinen MR (1990) Diabetes, hypertriglyceridemia and high density lipoprotein. In: Carlson LA (ed) Disorders of HDL. Smith-Gordon, London, pp 137-144

Received: 2 July 1992

and in revised form: 28 September 1992

Dr. J.Spjuth

Department of Internal Medicine

Central Hospital

S-371 85 Karlskrona

Sweden 